\section{Representações de língua/linguagem e ensino de Língua Portuguesa à luz do Círculo de Bakhtin}

\author{
Representations of language \\ and Portuguese Language \\ teaching according to the \\ Bakhtin Circle
}

Herman Wagner de Freitas REGIS (UNICAP) profhermanregis@yahoo.com.br Pollyanne Bicalho RIBEIRO (UFC) pollyanne_br@yahoo.com.br

Recebido em: 15 de maio de 2020. Aceito em: 19 de jun. de 2020.
REGIS, Herman Wagner de Freitas; RIBEIRO, Pollyanne Bicalho.

Representações de língua/linguagem

e ensino de Língua Portuguesa à luz do Círculo de Bakhtin. Entrepalavras, Fortaleza, v. 10, n. 2, e1926, p. 1-22, maio-ago/2020. DOI: 10.22168/22376321-21926

Resumo: Neste trabalho, objetivamos discutir o engendramento de representações sociais a partir dos efeitos da abordagem de língua/linguagem presente em gramáticas voltadas para o ensino fundamental $\left(6^{\circ}\right.$ ao $9^{\circ}$ ano). Como referencial teórico, operamos com os pressupostos do Círculo de Bakhtin (BAKHTIN, 2008, 2011; VOLÓCHINOV, 2017) entrecruzados com a Teoria das Representações Sociais (MOSCOVICI, 1961; ABRIC, 2001; JODELET, 1989). Defendemos que a identificação do acervo representacional mobilizado pelos livros didáticos pode colaborar para repensarmos a prática formativa dos docentes, sobretudo, quanto aos seus desdobramentos no contexto escolar. Nesse sentido, analisamos os conceitos de língua/linguagem presentes em duas gramáticas do ensino fundamental, a fim de identificarmos problemas de ordem teórico-metodológica no ensino de Língua Portuguesa à luz da Teoria Dialógica do Discurso. As gramáticas analisadas nos demonstraram que a língua/linguagem ainda é abordada de maneira antidialógica e homogênea. A partir do mapeamento do acervo representacional concernente à língua/linguagem, acreditamos que é possível instaurar reflexões sobre a prática formativa, visando garantir um ensino produtivo, ancorado no dialogismo bakhtiniano.

Palavras-chave: Teoria Dialógica do Discurso. Representações Sociais. Gramática. 
V. $10(2)$

$1-22$ maio-ago 2020
Abstract: In this work, we aim to discuss the formation of the social representations from the effects of the language approach in grammars directed to middle school. As a theoretical reference we operate with notions of the Bakhtin's Circle (BAKHTIN, 2008, 2011; VOLÓCHINOV, 2017) interwoven with the Theory of Social Representations (MOSCOVICI, 1961; ABRIC, 2001; JODELET, 1989). We defend that the identification of the collection that represents the teacher mobilized by the textbooks can collaborate to rethink the formative practice of teachers especially as to its unfoldings in the school context. In this direction, we analyze the concepts of language present in two grammars of middle school to identify theoretical-methodological problems in Portuguese language teaching according to Dialogic Discourse Theory. The grammars analyzed showed us that language is still approached in an antidialogical and homogeneous way. From the mapping of the representational collection concerning the language, we believe that it is possible to establish reflections on formative practice, to ensure a productive teaching, anchored in Bakhtinian dialogism.

Keywords: Dialogic Discourse Theory. Social Representations. Grammar.

\section{Introdução}

A defesa aqui investida diz respeito à necessidade de analisarmos, nas gramáticas de Língua Portuguesa do Ensino Fundamental, representações sociais (RS) de língua/linguagem para refletirmos sobre os efeitos delas no ensino de Língua Portuguesa na realidade escolar brasileira. Acreditamos que o discurso funda e atualiza representações e, portanto, (re)conhecer o papel das RS para as escolhas teórico-metodológicas empreendidas no ensino de LP nos parece um caminho profícuo para a satisfação de objetivos pedagógicos visados pela demanda educativa atual.

Selecionamos, portanto, duas gramáticas de LP do EF do $6^{\circ}$ ao $9^{\circ}$ ano e nos detivemos nos capítulos que tratam de língua/linguagem (MESQUITA; MARTOS, 2009; CEREJA; MAGALHÃES, 2012). Tais capítulos mostraram que as concepções de língua/linguagem espelham, ainda hoje, as prescrições trazidas pelas gramáticas normativas da LP em geral. A proposta didática defendida por essas gramáticas traz metodologias homogeneizadoras, sequências didáticas "cristalizadas" (ROJO, 2013), tratando-se, muitas vezes, do velho escamoteado de novo. Esse cenário, por sua vez, corrobora para o repertório representacional do professor que irá atuar a partir do bojo de representações apreendidas nos manuais, documentos, etc. (natureza prescricional). O professor acaba, de certa forma, sendo levado a seguir a sistematização dos conteúdos e a metodologia que aparecem nos livros didáticos dado ao caráter coercitivo desses recursos.

De posse dos resultados deste estudo, o professor poderá balizar as suas escolhas entre o que é de cunho prescricional (trabalho prescrito) e 
o que de fato acredita ser devido ou possível trabalhar no cotidiano da sala de aula no ensino de LP. Acreditamos que o reconhecimento de maneiras de representar a língua/linguagem nas gramáticas pode levar a uma nova configuração dessa disciplina, visto que as representações sociais, que é "uma forma de conhecimento, socialmente elaborada e compartilhada, que tem um objetivo prático e concorre para a construção de uma realidade comum a um conjunto social" (JODELET, 1989, p. 36) precisam ser, dialogicamente, refletidas à luz da Teoria Dialógica do Discurso (TDD).

A aproximação das duas teorias (TRS e TDD) se dá em razão de reconhecermos que as representações são constructos simbólicos engendrados nas trocas dialógicas estabelecidas entre sujeitos sociais. Assim, é na interação que o acervo representacional é formulado, atualizado e transformado. O funcionamento das representações é garantido pela dimensão axiológica da linguagem (BAKHTIN, 2008, 2011; VOLÓCHINOV, 2017), visto que nos valemos dos quadros de saberes comuns para imprimir no ato comunicativo aspectos valorativos, volitivos e, ao mesmo tempo, é também garantia dessa dimensão, pois as representações são mobilizadas para que tenhamos o enunciado concreto, ou seja, a alternância dos sujeitos, as trocas responsivas.

Quanto ao trabalho prescrito, Amigues explica que "as prescrições não servem apenas como desencadeadoras da ação do professor, sendo também constitutivas de sua atividade" (2004, p. 42). A partir dessa assertiva, podemos dizer que as prescrições compõem o nosso agir e quem somos como professores, pois não se pode afirmar que tudo o que é prescrito é realizado, haverá sempre espaço para a singularidade do sujeito, sua marca autoral, para as investidas naquilo que é necessário para o desenvolvimento dos alunos no dia a dia escolar.

Também sabemos que não é tudo o que é prescrito ou desejado pelo professor que se pode empreender em sala de aula, visto que outros fatores como, por exemplo, condições de trabalho, podem impedir o agir professoral. Nesse caso, haverá um conflito entre o trabalho prescrito e/ ou planificado e o real do trabalho, o que, por conseguinte, demonstra que determinadas atividades planejadas para o professor não podem ser realizadas, o profissional em questão pode se encontrar diante de impedimentos externos, sem, portanto, ter o controle total das ações esperadas para o desenvolvimento de seu métier.

Assim, diante do trabalho prescrito e o trabalho realizado, haverá também o real do trabalho, ou seja, aquilo que não foi possível realizar de fato por diversas razões que se impõem ao agente profissional (cf. LOUSADA, 2006). 
V. $10(2)$

$1-22$

maio-ago

2020

Os dados das análises das gramáticas nos apontam para o fato de que os currículos (trabalho prescrito), realizados a partir dos livros didáticos ou das gramáticas usadas em sala de aula, não estão tão alinhados à TDD, a qual propõe uma ressignificação de conceitos como o de língua, linguagem, gêneros discursivos etc. Tais conceitos são, frequentemente, abordados de forma superficial, pois ainda é muito forte a representação de que língua/linguagem é um conjunto de regras gramaticais, um sistema abstrato, formal, sem considerar o caráter textual-interativo, o dialogismo ea alternância dos sujeitos, pressupostos caros para a TDD na proposição de uma formação enunciativa. Nesse contexto, Rojo (2013) chama atenção para a dificuldade de atualizar objetos de ensino a partir da atual demanda educacional.

A gramática da LP, assim como o livro didático, dada a sua natureza prescricional, pode ser um dos responsáveis pela homogeneização dos conteúdos e das metodologias, visto que corrobora para a abordagem de objetos de ensino da língua. Assim como Rojo (2013) alerta para o problema da implicação do uso do livro didático nas escolas, as análises, neste artigo, foram reveladoras de problemas de ordem teórico-metodológica do ensino de LP no Ensino Fundamental, sobretudo, no que diz respeito à resistência de se afastar de representações sobre língua/linguagem cristalizadas, pouco condizentes com as contribuições da Linguística Aplicada para o ensino.

É preciso trazer à luz conceitos como heterogeneidade, gênero, enunciado, enunciação, dialogismo, etc. elaborados pela Análise Dialógica do Discurso (ADD), a fim de que haja uma atualização das representações sobre língua/linguagem e que se alcance uma efetiva mudança na abordagem desses conceitos em sala de aula. No bojo desse processo formativo instaurado pelo reconhecimento das concepções apontadas, modos de agir em sala de aula poderão ser revistos e reconfigurados para o alcance dos objetivos pedagógicos traçados para o ensino de LP.

É preciso defender o ensino de LP baseado nos pressupostos dialógicos da linguagem, partindo do texto entendido como enunciado concreto. Para uma proposta dialógica de ensino da língua, devemos considerar os aspectos históricos, ideológicos, culturais nas análises empreendidas, pois "o discurso só pode existir de fato na forma de enunciados concretos de determinados falantes, sujeitos do discurso" (BAKHTIN, 2016, p. 28). Esse posicionamento vai de encontro às pressões das avaliações externas, como, por exemplo, do Sistema de Avaliação da Educação Base (SAEB), com sua gama de descritores, que acaba por 
impor ao professor que ele siga o descritor em sala de aula para que seus alunos tenham uma participação exitosa na avaliação, levandoos a uma prática de treinamento para o alcance de bons resultados. Quando o resultado da avaliação externa se torna um fim por si mesmo, a visão de língua/linguagem acaba sendo fragmentada, engessada, descontextualizada.

A posição desejada pela Linguística Aplicada quanto ao ensino de LP, no entanto, seria de tomarmos os descritores de uma determinada matriz curricular como um ponto de partida, que irá orientar a prática de sala de aula, mas não a define, levando o professor à assunção de sua condição de ator que ressignifica a prescrição para infinitas hibridizações da linguagem (MOITA LOPES, 2006), conforme os diversos contextos sugerem, de acordo com as nossas representações e as demandas da sala de aula.

Para o desenvolvimento deste estudo, este artigo contempla duas seções, e, em cada uma delas, propõe-se o diálogo entre a TRS e a $\mathrm{ADD}$, a fim de identificar lacunas concernentes ao ensino da LP.

A primeira seção expõe uma aproximação entre a TRS e a ADD, a fim de demonstrarmos os efeitos representacionais para o ensino de LP e, particularmente, para refletirmos sobre as representações de língua/linguagem, tomando como base os pressupostos bakhtinianos.

$\mathrm{Na}$ segunda seção, haverá a análise de duas gramáticas da LP do EF do $6^{\circ}$ ao $9^{\circ}$ ano (MESQUITA; MARTOS, 2009; CEREJA; MAGALHÃES, 2012), particularmente, dos capítulos que tratam de língua/ linguagem, recorrendo aos princípios teóricos da ADD (BAKHTIN, 2011; VOLÓCHINOV, 2017), objetivando identificar problemas que reduzam o enfoque linguístico demasiadamente normativo, taxonômico e ceda espaço para a inserção da formação discursiva.

\section{Representações sociais e a Teoria Dialógica do Discurso: aproximações possíveis}

Iniciemos essa discussão por Bakhtin (2008), que faz referência ao discurso polifônico, às formas de alteridade como parte do discurso, ao analisar, em Problemas da Poética de Dostoiévski, o romance de Fiódor Dostoiévski, escritor russo. Nessa obra, Bakhtin conceitua discurso como "a língua em sua integridade concreta e viva e não a língua como objeto específico da linguística, obtido por meio de uma abstração absolutamente legítima e necessária a alguns aspectos da vida concreta do discurso." 
V. $10(2)$

$1-22$

maio-ago

2020

(BAKHTIN, 2008, p. 207). Para Bakhtin, a língua não pode ser tratada como algo construído no campo da abstração, mas como um constructo "concreto", "vivo", "polifônico" (formado por diversas vozes), marcado pela alteridade, que é algo constituído pelo dialogismo no sentido da formação da consciência humana e da subjetividade.

O Círculo de Bakhtin entende alteridade como condição para a construção dos valores dos sujeitos, da comunidade, do grupo social, em qualquer das práticas sociais, já que o mundo concreto é fundado nos centros de valores do eu e do outro. Assim, a alteridade é garantia para a re(construção) da consciência, ou seja, "a própria capacidade de ter consciência está baseada no outro" (HOLQUIST, 1994, p. 18); o outro, portanto, chega a mim e me constitui através das interações sociais. No âmbito educacional, as representações são formuladas e atualizadas nas práticas sociais, no confrontamento das representações já sedimentadas, consagradas com as representações advindas das novas experiências.

Py (2000, 2004), ao tematizar a dinâmica das representações sociais (cf. MOSCOVICI, 1961), propõe que elas sejam vistas de duas formas: as representações de referência (RR) e as representações de uso (RU), sendo as primeiras mais estáveis, o que concluímos ser mais suscetíveis a produzir a força centrípeta (convergência); e as segundas mais dinâmicas, responsáveis pela força centrífuga (divergência) (MATENCIO; RIBEIRO, 2009).

A resultante dessas duas forças (centrípeta e centrífuga) geraria efeitos nos modos de produzir sentidos sobre os objetos do discurso. As interações, portanto, viabilizariam uma atualização das RR através da força centrífuga provocada pela RU.

Abric (1986, p. 15-18) enumera quatro funções essenciais das representações sociais: i) a função do saber, visto que elas viabilizam aos membros construírem conhecimentos em face do quadro de crenças que compõem o acervo do seu grupo de pertença; ii) a função identitária por permitirem aos sujeitos o reconhecimento do papel de membro, identificando semelhanças e diferenças inter/intragrupais; iii) a função de orientação por guiar ações e reações diante do acervo e; iv) a função justificativa por possibilitarem avaliações a partir de tomada de posicionamentos.

O professor de LP, ao se deparar com as demandas de seu métier, mobilizará representações sociais comuns, ordinárias, (COHENSCALI, 2000) em um determinado espaço de trabalho (a escola), e, por meio da alteridade, (re)construirá ou atualizará representações marcadas muitas vezes pelo monologismo. 
Essas primeiras noções básicas nos subsidiam, preliminarmente, a repensar como as gramáticas, enquanto importante recurso didático, podem reforçar a composição das representações convergentes com a RR de um olhar acrítico, que concebe a língua de maneira monológica, estanque e homogeneizadora. Contestar tal visão é necessário e ampliar essa perspectiva, recorrendo, para tanto, aos pressupostos bakhtinianos concernentes à concepção língua/linguagem, possibilitaria rever o quadro representacional, e, por conseguinte, estabelecer uma nova ordem representacional, um novo feixe de RR.

Debater aspectos teórico-metodológicos que deveriam estar nos materiais didáticos e evidenciar as lacunas existentes corroboraria para entender a língua/linguagem calcados nos preceitos da alteridade e do dialogismo em uma relação histórica, sociológica, etc. dos envolvidos em um processo, que não seja oriundo de uma visão distópica da língua/ linguagem, mas fruto das relações interpessoais do sujeito com seus outros.

É preciso que haja mudanças nas $\mathrm{RR}$, sejam elas sobre o ensino, sobre a figura do professor, sobre o objeto de aprendizagem, sobre o material didático. Debruçar-se criticamente sobre o material didático, aqui, particularmente, sobre as gramáticas, é trazer à discussão para dentro de sala de aula os preceitos da TDD, visando ressignificar conceitos e criar metodologias que descristalizem o ensino em sala de aula.

Por exemplo, em uma aula cuja temática seja os gêneros discursivos, não é somente o texto em si e os elementos linguísticos que devem ser explorados, mas como eles indiciam as diferentes vozes que atravessam o enunciado (BAKHTIN, 2011). O professor deverá ter em mente que o conteúdo temático, o estilo e a estrutura composicional trazem no seu funcionamento as inúmeras vozes sociais.

No sentido de buscar tal mudança de paradigma, precisamos promover reflexões sobre o papel da alteridade e do dialogismo ao ensinar LP (educação dialógica alteritária), conforme Bakhtin (2011), Volóchinov (2013; 2017). O foco do ensino deveria se voltar para o enunciado concreto, para a linguagem, e não para o sistema, a língua. Para a ADD, o sentido é construído na interação, assim, o outro importa sobremaneira nessa construção, visto que "a palavra é uma ponte que liga o eu ao outro. Ela apoia uma das extremidades em mim e a outra no interlocutor. A palavra é o território comum entre o falante e o interlocutor" (VOLÓCHINOV, 2017, p. 205). 
V. 10 (2)

1-22 maio-ago 2020
Lançando um olhar sobre Bakhtin (2011), necessário se faz reconhecer que o sentido, diferentemente do significado, faz parte do diálogo. O significado está para a abstração, afasta-se da palavra viva, não expressa aspectos emocionais e volitivos dos seres sociais, já o sentido possui concretude, dinamismo e contexto. "A relação com a coisa (em sua materialidade pura) não pode ser dialógica (isto é, não pode ser uma conversa, discussão, acordo, etc.). A relação com o sentido é sempre dialógica." (BAKHTIN, 2016, p. 97). Contudo, o que ainda temos, muitas vezes, nos materiais didáticos, é um ensino de LP centrado, prioritariamente, na questão do significado das palavras e não no sentido que possuem nos mais diversos contextos de fala.

Esse problema advém também da falta de questionamento dos conceitos fechados das gramáticas. A ressignificação das representações seria deflagrada pelo entendimento de que a língua/linguagem, ancoradas no escopo dialógico, é configurada pela "situação de interação" decorrentes "das diferentes determinações (sócio-históricas, culturais, psicológicas) dessa situação" (LIPIANSKY et al., 1990, p. 24). Essa compreensão pode levar a mudanças de comportamento na escola, provocar diálogos constantes entre professores, impactar suas práticas de sala de aula, ao fazer escolhas que vão ao encontro de pensar sobre o sentido das palavras em contextos de uso de fala.

Outra noção que merece atenção é a da enunciação. Entender que nos comunicamos através de enunciados concretos, que os interlocutores são sujeitos situados, que operam com recursos linguísticos, textuais e discursivos a fim de satisfazer seu projeto de dizer. A língua/linguagem é fenômeno histórico, produtora e catalisadora de representações sociais através das quais nos (re)construímos e (re)construímos o mundo.

Entretanto, as análises das gramáticas indiciam que a abordagem de língua/linguagem assume, geralmente, um caráter descritivo, mesmo quando o conteúdo ensinado são os gêneros discursivos. Isso ocorre em razão de se operar com uma RR de língua que não envolve as vozes sociais do enunciado, a alternância dos sujeitos sociais. É preciso que os interlocutores acessem outros acervos, a fim de colocar em xeque o que está dado, contestem e criem novas formas de se relacionar com o mundo, pois a língua é uma atividade, não é um objeto homogêneo, externo ao falante. (VOLÓCHINOV, 2017).

Nessa perspectiva, é notório que o ensino de LP, incluindo o uso de materiais didáticos como o LD e a gramática, poderia contemplar 
as contribuições da Teoria Dialógica do Discurso, no sentido de reconhecer "a língua como um conjunto de práticas enunciativas e não como forma descarnada." (MARCUSCHI, 2008, p. 19). A aula de LP, por sua vez, ganharia consistência, pois situaria a língua no campo do discurso (MARCUSCHI, 2008), transformando a sala de aula em um grande espaço de investigação, sendo a língua compreendida como uma atividade social (VOLÓCHINOV, 2017).

\section{Problemas de ordem teórico-metodológica no ensino de gramática da LP}

Para Rojo (2013), o livro didático, conforme já destacamos, cristaliza os currículos das escolas e, no nosso entendimento, a gramática de LP também cumpre esse papel, sendo, por isso, necessário olhar criticamente para os conteúdos e as metodologias presentes nesses recursos didáticos.

Em uma perspectiva sócio-histórica de base discursiva, o livro didático deve ser compreendido como um gênero do discurso (BUNZEN, 2005; BUNZEN, ROJO, 2005) e não como um suporte de textos, pois há uma imbricação de discursos no seu bojo (discurso científico, didático e cotidiano).

Do ponto de vista linguístico e discursivo, numa perspectiva sócio-histórica e cultural, o LDP é essencialmente, [...], um gênero do discurso (Bakhtin 1934-35, 1952-53) que procura sistematizar e organizar os conhecimentos escolares na forma de modelo(s) didático(s); por isso mesmo, não podemos deixar de perceber o sistema de valores que participa do processo de socialização e aculturação do público a quem se destina. Além disso, ele pode ser encarado como um instrumento pedagógico, uma vez que reflete as várias tradições, as inovações e as utopias de uma época. (BUNZEN, 2005, p. 18)

Mostraremos adiante, nas análises desenvolvidas neste artigo, que as concepções de língua/linguagem, quando são abordadas nas gramáticas, são constructos pouco aprofundados. Para o procedimento analítico, o corpus foi extraído de duas gramáticas (uma de cada série), voltadas para o ensino fundamental do $6^{\circ}$ ao $9^{\circ}$ ano (MESQUITA; MARTOS, 2009; CEREJA; MAGALHÃES, 2012), ambas compostas de textos de diversos "gêneros e contextos de circulação pertencente à cultura da escrita (jornalísticos, literários e de divulgação científica [...]" (ROJO, 2013, p. 164) de escritores (jornalistas, poetas, cronistas etc.) em geral do Sul e do Sudeste brasileiros. 
V. $10(2)$

1-22 maio-ago 2020

Quase a totalidade desses textos ressaltam a forma culta da língua, são gramáticas normativas que abordam a variação linguística, "nunca explorando variedades geográficas ou sociais da língua efetivamente em uso" (ROJO, 2013, p. 164). Nessas gramáticas, encontramos, geralmente, fragmentos de textos dos mais diferentes gêneros, tendo como base estrutural teoria e exercícios de aplicação, que funcionam, meramente, como resposta e reforço para os conceitos linguísticos nelas estabelecidos. É, portanto, uma sistematização, geralmente, mecanicista que não propõe um olhar dialógico sobre a língua/linguagem.

As duas obras analisadas são formadas de unidades que por sua vez estão constituídas de capítulos, mantendo a mesma organização didática: inicia com uma seção sobre língua/ linguagem, seguida de fonética (ou fonologia), depois morfologia, sintaxe, semântica e estilística. Nessas seções, encontramos ainda a seguinte estruturação: inicia-se com um texto que serve de exemplo à teoria que foi abordada ou que foi usado para que partes dele possam servir de exemplos para ilustrar conceitos descontextualizados, desvinculados do uso da língua/linguagem no dia a dia.

Os exercícios presentes nessas gramáticas são de ensino de língua calcado em um sistema repetitivo de preparação e avaliação para fixação de conteúdos específicos. A proposta de expressão oral nas gramáticas analisadas é, praticamente, inexistente, um contraponto à orientação diálógica que é, naturalmente, um fenômeno próprio a todo discurso (VOLÓCHINOV, 2017).

Ponzio (2008, p. 164), ao tematizar os postulados do Círculo de Bakhtin, salienta que o tema ou sentido pressupõe uma compreensão ativa, uma resposta, um posicionamento, referindo-se à situação concreta, ou seja, tratar-se-ia da expressão do irrepetível da interação verbal; já o significado, por sua vez, deve ser compreendido como tudo o que o signo apresenta com caráter de reprodução, de estabilidade, aquilo que é da ordem do repetível.

[...] na vida da linguagem, a significação é apenas uma base para que se instaure, de modo provisório e instável, algum sentido, nunca pleno, mas justamente prenhe de possibilidades imprevistas de expressão e apreensão. Para Bakhtin, 'puro' é sinônimo de abstração, é pleno, tomado em sua integralidade. (SOBRAL, 2019, p. 68-69) 
Após essa reflexão inicial, passemos, portanto, à análise do corpus. Vejamos a priori três pontos de reflexão, seguidos de excertos extraídos de Mesquita e Martos (2009) para identificarmos questões do ensino de LP no EF em termos de conteúdos e de metodologias que podem levar a uma compreensão monológica da língua:

(1) Significado (significação) x sentido das palavras (tema): uma palavra, em qualquer espaço, pode ser um texto. Na gramática em análise, palavras soltas usadas como exemplo de uma regra são frequentes. Tomando uma dessas palavras para analisar em sala de aula, seria interessante não se prender ao significado, mas ao sentido nos mais variados contextos para que o aluno não compreenda a linguagem como algo fixo, determinado. Se não há o trabalho com os contextos culturais, sociais e ideológicos etc., e quando se opta a trabalhar a palavra como algo estanque, com o significado fixo e descontextualizado, a representação da língua que o aluno terá é de algo monológico e homogêneo. Reconhecemos que todo recurso didático (livros didáticos, gramáticas etc.) não contempla tudo o que seria necessário ser aplicado em sala de aula. É preciso que o professor, no dia a dia do seu métier, faça as devidas adequações, adaptações, ampliações. O docente deve criar metodologias que concebem o sujeito, ator do processo de aprendizagem como um "indivíduo concreto, real, único, ancorado numa situação, que tem a particularidade de estar em 'diálogo' permanente com a fala dos outros indivíduos" (SÉRIOT, 2015, p. 15).

Em Mesquita e Martos (2009, p. 16), como se pode ler no excerto 1, temos um texto seguido de uma análise puramente linguística e quatro palavras usadas como exemplos. Ademais, na continuação da referida página, não há outras abordagens referentes ao texto em questão. 
V. $10(2)$

$1-22$

maio-ago 2020

Excerto 1 - Texto seguido de análise linguística e quatro exemplos

Observe as palavras destacadas no trava-língua a seguir:

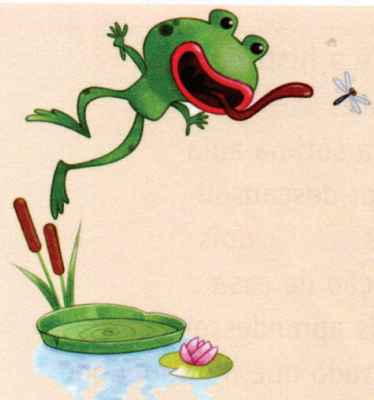

\section{Sapo no saco}

Olha o sapo dentro do saco

0 saco com o sapo dentro

0 sapo batendo papo

E o papo soltando vento.

(http://www.qdivertido.com.br/

verfolclore.php?codigo $=22>$, acessado em 4 jan. 2009.)

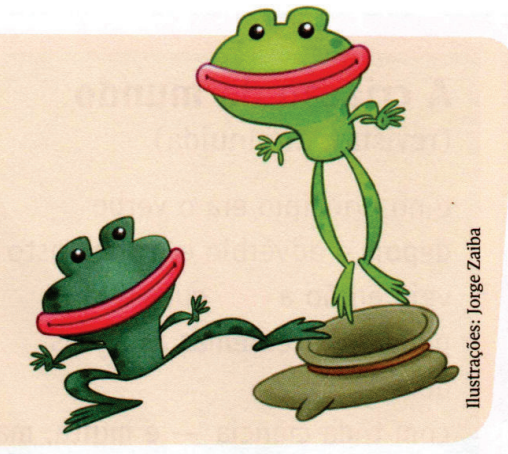

A diferenciação de significado é dada pelos fonemas destacados a seguir:

saco $\longrightarrow$ sapo

sapo $\longrightarrow$ papo

Fonte: Mesquita e Martos (2009, p. 16).

Esse modelo de abordagem, extraído de Mesquita e Martos (2009), que também é muito encontrado nos livros didáticos de LP do $\mathrm{EF}$, somado aos outros que adiante mostraremos extraídos de Cereja e Magalhães (2012), podem ser reveladores de conceitos relacionados com língua, linguagem, texto, gênero e discurso não alinhados com a perspectiva interacional. Ademais, é o protótipo da ausência da análise da função social, dos possíveis suportes ${ }^{1}$, dos domínios discursivos, da alternância do sujeito, do enunciado concreto, da enunciação etc.

Como é possível notar, o texto é pretexto para o ensino da gramática, pois, em geral, não há menção das condições de produção de sentido, do lugar de fala dos sujeitos, abordagem da dimensão temporalespacial etc. O que se percebe são representações de língua/linguagem distantes da concepção bakhtiniana sobre linguagem, porque enfocam, entre outros aspectos, o enunciado meramente como um fenômeno da língua, indiferente da dimensão axiológica que lhe é peculiar.

(2) Conceito de linguagem e língua: Em Mesquita e Martos (2009, p. 09), o conceito de linguagem (ver excerto 2) segue a mesma representação de língua do excerto 01, assim como o de língua (ver excerto 3) em Mesquita e Martos (2009, p. 12).

\footnotetext{
${ }^{1}$ Para Marcuschi (2003), o suporte pode ser entendido como um lócus físico ou virtual, com um determinado formato, que se presta à condição de base ou ambiente de fixação do gênero materializado como texto.
} 
Excerto 2 - Conceito de linguagem

Linguagem, língua e Gramática

\begin{abstract}
A todo momento, o ser humano está em comunicação. Para comunicar-se com os seus semelhantes, ele usa vários recursos, como palavras, gestos, desenhos, movimentos, imagens e sons.

A capacidade de usar tais recursos para comunicar-se chama-se linguagem. É por meio dela que o ser humano transmite as emoções e os pensamentos e consegue viver e trabalhar em comunidade.

Fonte: Mesquita e Martos (2009, p. 09).
\end{abstract}

Excerto 3 - Conceito de língua Língua

\begin{abstract}
A língua, ou o idioma, que cada povo utiliza no seu cotidiano também é um código, um sistema de palavras organizado de forma a estabelecer a comunicação ou permitir, por exemplo, a expressão de um pensamento, uma ideia ou uma emoção.

A língua portuguesa é o nosso código de comunicação, aquele que empregamos diariamente para conversar com os colegas, comentar o último jogo do campeonato, anotar um recado, escrever uma carta ou um e-mail etc.
\end{abstract}

Fonte: Mesquita e Martos (2009, p. 12).

Nesses casos, o professor de LP deve refletir as concepções de Volóchinov/Bakhtin, atentando para os princípios sociointeracionistas da língua na abordagem de conceitos linguísticos; essa prática se afasta da ideia de "considerar a língua como um sistema autônomo e como simples forma." (MARCUSCHI, 2008, p. 16).

Sabemos que não se trata de trazer todo o quadro teórico da TDD para as gramáticas de ensino da LP. Entretanto, a transposição dos conceitos para o material didático deve ocorrer de maneira mais cuidadosa, menos simplista, porque, caso contrário, esses excertos não serão capazes de provocar mudanças substanciais no quadro representacional (RR) pautado pelos alunos sobre língua/linguagem.

Nesse sentido, partindo dos pressupostos bakhtinianos (BAKHTIN, 2011) de que são duas disciplinas distintas para o estudo da linguagem verbal: a linguística, que trata unicamente do estudo gramatical, e a metalinguística ${ }^{2}$, que trata da dinâmica das práticas socioverbais concretas presentes nas relações dialógicas. Baseando-se no arcabouço teórico-metodológico cunhado pelo Círculo de Bakhtin, é válido ressaltar a proposta de uma "metalinguística" para tratar o discurso, compreendido como "a língua em sua integridade concreta e viva" e suas relações dialógicas, as relações de sentido desencadeadas (BAKHTIN, 2008, p. 207).

\footnotetext{
${ }^{2}$ Muitos estudiosos da TDD preferem o emprego do termo translinguístico referido, dentre outros, por Todorov (1981), para não confundir com o conceito de metalinguística comumente empregado nos estudos linguísticos. Vale salientar que embora a translinguística e a linguística tenham como objeto a língua/linguagem, a abordagem se efetiva "sob diferentes aspectos e diferentes ângulos de visão", sendo a primeira relacionada às relações dialógicas e a segunda, às relações lógicas (BAKHTIN, 2008, p. 207).
} 
V. $10(2)$

$1-22$

maio-ago

2020

Os conceitos de língua e de linguagem em Mesquita e Martos (2009) são tão somente linguísticos, distantes da "língua em sua totalidade concreta e viva" (BAKHTIN, 2008, p. 207). Percebe-se o destaque, nessa gramática, para o entendimento da língua representada como código.

Notam-se, nos excertos já analisados, elementos que permitem perceber uma representação de língua entendida como instrumento de comunicação, como expressão de pensamento/emoções, sendo a dimensão interativa colocada de maneira periférica. Dessa forma, a ausência de aspectos mais precisos da interação social provoca uma visão limitadora, reforçando, pois, as RR de língua prescritiva.

Somente na última linha do excerto 03, há uma tímida menção de aspectos relacionados à dimensão social, quando os gêneros são citados (comentário, anotação, recado, carta e e-mail). No entanto, não se explora a concepção de gênero e não a relaciona com as esferas sociais, levando a depreender que o sistema é o que importa para a prática comunicativa.

Para Bakhtin (2011), a linguística é insuficiente para o estudo da comunicação verbal embora seja necessária. Para ele, os gêneros dos discursos, as relações dialógicas, a natureza dos enunciados concretos estão no plano do estudo da linguagem. Portanto, é importante que os gramáticos não excluam a linguística das gramáticas, nem os professores a abandonem em suas aulas, mas que ambos avancem no sentido de uma análise do discurso, de um estudo voltado para os aspectos socioverbais concretos, proporcionando tanto a abordagem linguística quanto dialógica. Para isso, devem retirar "a língua do campo da estrutura para situá-la no campo do discurso em seu contexto sociointerativo." (MARCUSCHI, 2008, p. 21).

(3) Atividades de aplicação do conhecimento: Em Mesquita e Martos (2009, p. 22), assim como na abordagem da teoria, os exercícios propostos abordam apenas a análise linguística limitada a diferenciar letras de fonemas e a motivar o aluno a conceituar esses termos. (Ver excerto 4). 
Excerto 4 - Exercícios

(1) Estudamos neste capítulo, entre outros assuntos, as diferenças entre letra e fonema. Leia o texto a seguir e faça o que se pede:

\section{0 rato roeu}

0 rato roeu a roupa do rei de Roma, o rato roeu a roupa do rei da Rússia, o rato roeu a roupa do Rodovalho... o rato a roer roía.

E a Rosa Rita Ramalho do rato a roer se ria. A rata roeu a rolha da garrafa da rainha.

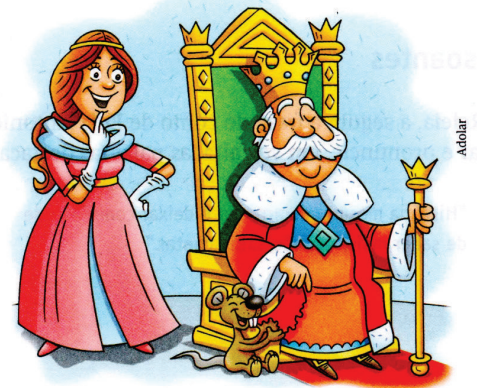

Fonema e e elemento que estabelece a diferenç̧a de significado entre as palavras. Com a mudança de um

a) Explique o que é fonema a partir da diferença entre as palavras rato e rata.

b) Quais são as diferenças de fonemas entre as palavras Rita e rata?

c) Com base na resposta do item anterior, explique o que é letra.

d) Explique o emprego da letra $\mathbf{r}$ e do fonema correspondente nas palavras garrafa rainha. Para que a letra r represente o mesmo fonema (VR) nas duas palavras, é necessário dobrá-la na palavra na sua pronúncia.

Fonte: Mesquita e Martos (2009, p. 22). ${ }^{3}$

Para Volóchinov (2017), a linguística, notadamente explorada no excerto 4, pelo lado da perspectiva formal, revela um objetivismo abstrato, foca-se o sistema, não se consideram os aspectos emocionais e volitivos que compõem o enunciado concreto (VOLÓCHINOV, 2017). Para ele, a linguística precisa ser redirecionada a partir da inserção da enunciação como objeto. No excerto 4, se pautarmos a enunciação na prática de ensino, o texto deveria ser representado pela "natureza social da linguagem" (VOLÓCHINOV, 2013, p. 157), analisando a participação falante/ouvinte, buscando reconhecer aspectos ideológicos presentes em cada enunciado etc. $\mathrm{O}$ excerto 4, na atividade, apresenta a representação de texto descontextualizado, desatrelado do mundo social, que poderá ser entendido pelo aluno como não autêntico. Se a ADD fosse considerada pelos autores, teríamos exercícios que levariam o aluno a buscar entender as razões de produção do texto e isso seria possível, por exemplo, se também aspectos sociais, históricos, ideológicos fossem considerados.

Na segunda gramática analisada, Cereja e Magalhães (2012), a abordagem é similar. O primeiro capítulo inicia com uma atividade na qual uma tira é o gênero a ser explorado. (Ver excerto 5).

\footnotetext{
3 Embora os exemplos advenham do livro do professor, não nos detivemos às sugestões de respostas aos enunciados propostos. Focamos apenas nos enunciados que coincidiriam também com a versão do livro dos alunos.
} 
V. $10(2)$

1-22

maio-ago

2020

Excerto 5 - Exercícios

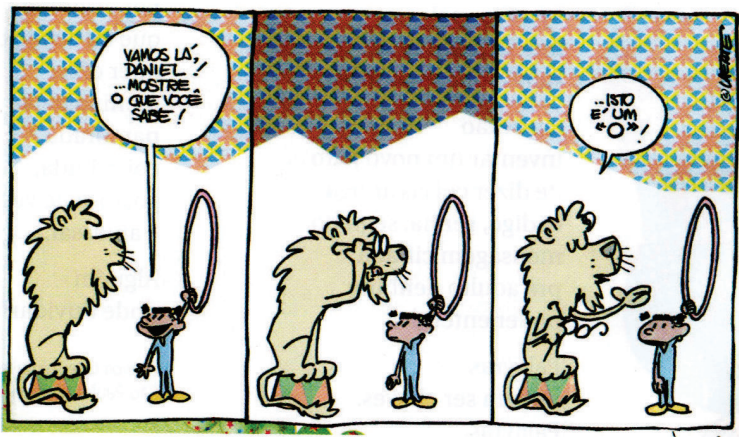

(Suriá contro o dono do circo! São Paulo: Jacarandá, 2003. p. 15)

1. Suriá, personagem de Laerte, é uma menina cujos pais moram e trabalham num circo

a) No 1 ? quadrinho da tira, quem é o interlocutor de Suriá, ou seja, com quem ela está falando?

b) Ao dizer a Daniel "Mostre o que você sabe", o que Suriá esperava dele?

c) O que levou você a chegar a essa conclusão? o fato de Daniel ser um leāo adestrado e estar num circo

2. Na linguagem dos quadrinhos, é comum o humor ser construído a partir da quebra de expectativas. Observe o 2\% e o 3 ? quadrinhos.

a) O que os óculos de Daniel sugerem sobre ele?

b) Por que a resposta do leão surpreende, quebrando a expectativa?

3. Quando a unidade básica da linguagem é a palavra, dizemos que se trata de linguagem verbal; quando não é a palavra, dizemos que se trata de linguagem não verbal; e, quando combina as duas, linguagem mista. Na tira de Laerte, foi utilizada linguagem verbal, linguagem não verbal ou linguagem mista? Justifique sua resposta. Foi utilizada a linguagem mista, pois há palavras (linguagem verbal) e desenhos (linguagem näo verbal).

Fonte: Cereja e Magalhães (2012, p. 12).

No excerto 5, os autores iniciam informando de quem se trata uma das personagens da tira: "menina cujos pais moram e trabalham no circo". No entanto, essa informação não favorece em nada o aluno a responder às questões. A proposta do ícone "Construindo o conceito" é para que o aluno consiga, a partir da atividade, formular o conceito, mas a própria questão acaba trazendo respostas, como, por exemplo, no enunciado do item $a$ da questão 1: "interlocutor com quem ela está falando". O mesmo ocorre na questão 3 quando são apresentados os conceitos de linguagem verbal, linguagem não verbal e linguagem mista.

$\mathrm{Na}$ atividade do excerto 5, os conceitos são abordados como constructos fechados (RR). Ainda que se aponte uma visão interacional da língua, o formato da atividade não colabora para uma elaboração dialógica, através da qual o aluno pudesse significar de maneira mais consistente e concreta o conceito de linguagem. A relação estabelecida entre autores e estudantes dificulta a troca, concedendo pouco espaço para reverberações.

Em Cereja e Magalhães, "a língua é um conjunto de sinais (palavras) e de leis combinatórias que permitem a interação verbal entre as pessoas." (2012, p. 19). Vejamos como, no excerto 6, esse conceito está sendo apresentado: 
Excerto 6 - Conceito de língua

"Se a gente inventar uma língua só nossa" Se a língua inventar uma gente só nossa

Note que, apesar de serem constituídos pelas mesmas palavras, os enunciados apresentam sentidos diferentes, porque a posição de algumas palavras na frase mudou.

Assim:

Língua é um conjunto de sinais (palavras) e de leis combinatórias que permitem a interação verbal entre as pessoas.

A língua, juntamente com outros elementos, como a dança, a música, as crenças, a culinária, etc., faz parte da cultura de cada povo. No Brasil, por exemplo, a língua portuguesa ganhou características muito diferentes das observadas na língua portuguesa falada em Portugal, em virtude da história de nosso povo e da influência que ela recebeu das línguas indígenas e africanas no período da colonização e, mais tarde, no século XX, das línguas trazidas pelos imigrantes europeus e asiáticos.

Fonte: Cereja e Magalhães (2012, p. 19).

Se o conceito de língua (CEREJA; MAGALHÃES, 2012) fosse formado com base no conceito de signo (VOLÓCHINOV, 2017), era preciso pautar a língua enquanto "conjunto de sinais" (CEREJA; MAGALHÃES, 2012, p. 19) que só se constituiria entre dois indivíduos socialmente organizados (VOLÓCHINOV, 2017). Nesse caso, esses "sinais" seriam sempre de natureza ideológica, e, por conseguinte, semiotizada. É preciso, efetivamente, que as abordagens presentes nas gramáticas considerem a responsividade (cf. BAKHTIN, 2011) nas interações, pois o aluno será reinvindicado a responder aos mediadores/interlocutores na construção do saber e, no âmbito da atitude responsiva, poderia transformar o acervo representacional demandado pela interação. Com essa visão, é preciso "recontextualizar a língua observando-a em seus contextos de uso e com ênfase no estudo do léxico, nos aspectos socioculturais, na interação e na visão cognitiva" (MARCUSCHI, 2008, p. 16).

Antecedendo ao conceito de língua no excerto 6, os autores citam os termos enunciados e sentidos, mas se limitam a uma análise linguística, tratando apenas da posição das palavras em uma frase, não considerando o contexto de produção do sentido, não operando, pois, com enunciados concretos. Precedendo ao conceito de língua, os autores fazem alusão a 
V. $10(2)$

$1-22$

maio-ago

2020

inúmeras linguagens (dança, música...) e ao fator histórico (influência de outras línguas sobre a língua portuguesa), mas a ideia central defendida consiste em entender a língua como "um conjunto de sinais (palavras) e de leis combinatórias que permitem a interação verbal entre as pessoas", salientando a RR de língua prescritiva, normativa.

No excerto 7, em Cereja e Magalhães (2012, p. 13-14), o cartum revela um discurso que abre espaço para análises da língua não mais como objeto autônomo, mas estritamente relacionado ao contexto de uso, mas não é o que acontece na abordagem por meio de exercícios.

Excerto 7 - Exercícios

\section{Exercícios}

Leia o cartum a seguir, de Santiago, e responda às questões 1 e 2.

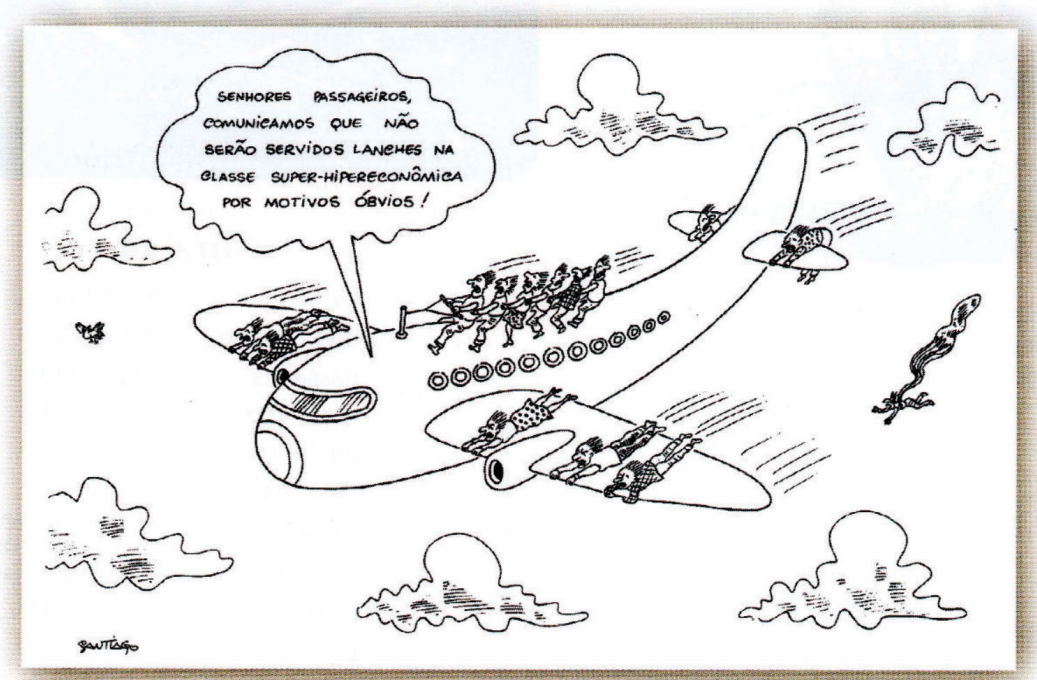

(Tintá fresca. Porto Alegre: L\&PM, 2004. p. 16.)

1. O balão de fala do cartum pressupõe uma interação pela linguagem. Responda:
a) Que tipo de linguagem foi utilizado nessa interação? Linguagem verbal.
b) Quem é o locutor nessa interação? E o locutário? Locutor: comissário(a) de bordo; locutário: passageiros da classe
c) Em que posição da aeronave fica a "classe super-hipereconômica"? Fora do avião.
d) Explique: Quais são os "motivos óbvios" pelos quais o lanche não será servido? O lanche voaria.

2. Considere agora o cartum como um todo. Ele é um texto que também permite a interação pela linguagem. Responda:
a) Quem são os interlocutores (locutor e locutário) nessa interação?
b) Que tipo de linguagem foi utilizado nessa interação? Linguagem mista

Fonte: Cereja e Magalhães (2012, p. 13-14).

Nesse excerto, as abordagens dos autores tendem a classificar e conceituar os termos linguísticos/discursivos. Para a proposta discursiva, a qual defendemos neste artigo, é preciso que se aborde 
o cartum enquanto discurso na perspectiva de que texto gere texto (BAKHTIN, 2011). Por exemplo, o termo "super-hipereconômica", no cartum, e os termos extraídos dos enunciados das questões e dos itens como "interação, linguagem, locutor, locutário, interlocutores" precisam ser evocados como textos, ou seja, devem ser assim tratados, pois, segundo Bakhtin, "onde não há texto não há objeto de pesquisa e pensamento." (2011, p. 307). A ironia, portanto, está no plano discursivo, o termo "super-hipereconômica" denuncia um lugar social de desprestígio, de desvalorização. O ato de compreender, para a ADD, já é uma resposta, visto que é preciso estar inserido nas práticas sociais para entender o jogo linguageiro (BAKHTIN, 2011).

Diante dessas reflexões, foi possível perceber que precisamos avançar para que as contribuições da TDD reverberem no âmbito escolar, provocando, de fato, uma atualização do quadro representacional mobilizado no ensino de Língua Portuguesa. As gramáticas, voltadas para o ensino de LP, precisam de fato se adequarem aos pressupostos dialógicos e se alinharem aos documentos oficiais: LDB (BRASIL, 1996), PCN (BRASIL, 1998) e BNCC (BRASIL, 2017), sejam no que tange aos conteúdos relacionados, sejam pelas abordagens e metodologias tematizadas.

Ao professor, caberá assumir um olhar crítico, fundamentado, estar atento para identificar lacunas a fim de complementá-las através de metodologias nas quais o aluno assuma o lugar de protagonista, seja responsivo. Nesse contexto, impõe-se também a urgência em propor formações continuadas à luz da TDD, para, inclusive, analisar, materiais didáticos disponíveis para o ensino de LP. Como desdobramento às formações, é possível pensar em processos avaliativos do acervo representacional mobilizado, o que poderá culminar em mudanças significativas dessas representações.

\section{Considerações finais}

Da análise feita das gramáticas, é possível afirmar que a representação prescritiva da língua ainda é a vedete de propostas teóricometodológicas de ensino de LP. Nesse sentido, não é difícil concluir que um dos impedimentos para a formação de uma nova configuração do ensino de LP se deve ao caráter pouco dialógico dos materiais didáticos. A nossa defesa é que devemos refletir sobre representações sobre língua/linguagem para (re)avaliar as escolhas teórico-metodológicas empregadas na sala de aula. 
V. $10(2)$

$1-22$

maio-ago

2020

Nesse sentido, à luz da TDD, os atores envolvidos com a prática formativa devem complementar os conteúdos elucidados pelos manuais, propor metodologias dialógicas, compor, coletivamente, o conhecimento em sala de aula.

Devemos resistir às forças que nos compelem a, passivamente, manter o status quo, determinado, quase sempre, por controles externos, como, por exemplo, as avaliações externas (ENEM, SAEB, SPAECE etc.). É preciso que contestemos o que é dado, o que chega pronto, como se não houvesse lacunas a preencher.

Ao longo deste artigo, as ideias do Círculo de Bakhtin foram abordadas para se discutir problemas de ordem teórica e metodológica identificados no ensino de LP do EF ao analisarmos as gramáticas. A partir dessa abordagem alinhada com a TRS, visamos entender como o ensino de LP continua, muitas vezes, calcado na representação de língua taxonômica, descontextualizada, antidialógica.

No final deste trabalho, concluímos que seria indispensável ressignificar as representações de LP do EF impostas pelos materiais didáticos. É preciso que as formações, continuada e inicial, invistam na ressignificação do quadro representacional de língua/linguagem e que fomentem um olhar crítico sobre os materiais didáticos para o planejamento de novas metodologias, novas abordagens de conteúdos. A premissa maior é a urgência de ressignificar a concepção de língua/ linguagem a partir de uma natureza histórica, sociológica etc.; é imperioso concebê-la como constructos não fechados, não presos à abstração, mas como fenômenos sócio-históricos. Enfim, essa concepção deveria ocupar o lugar de representação de referência nas aulas de LP.

\section{Referências}

ABRIC, J. C. Pratiques sociales et représentations. Paris: Presses Universitaires de France, 1986.

ABRIC, J. C. O estudo experimental das representações sociais. In: D. Jodelet (Ed.). As representações sociais. Rio de Janeiro: UERJ, p. 155-171, 2001.

AMIGUES, R. Trabalho do professor e trabalho de ensino. In: MACHADO, A. R. (org.). 0 ensino como trabalho: Uma abordagem discursiva. Londrina: Eduel, p. 35-53, 2004.

BAKHtin, M. Problemas da Poética de Dostoiévski. Tradução do russo, notas e prefácio de Paulo Bezerra. 4. ed. Rio de Janeiro: Forense Universitária, 2008. 
BAKHTIN, M. Estética da criação verbal. Prefácio à edição francesa: Tzvetan Todorov. Introdução e tradução do russo: Paulo Bezerra. 6. ed. São Paulo: Editora WMF Martins Fontes, 2011.

BAKHTIN, M. Os gêneros do discurso. Paulo Bezerra (Organização, Tradução, Posfácio e Notas). Notas da edição russa: Seguei Botcharov. São Paulo: Editora 34, 2016. 164 p.

BRASIL. LDB: Lei de diretrizes e bases da educação nacional. Brasília: Senado Federal, Coordenação de Edições Técnicas, 1996.

BRASIL. PCN: Parâmetros curriculares nacionais: terceiro e quarto ciclos do ensino fundamental: introdução aos parâmetros curriculares nacionais / Secretaria de Educação Fundamental. Brasília: MEC/SEF, 1998.

BRASIL. BNCC: Base Nacional Comum Curricular. Brasília: MEC, 2017.

BUNZEN, C. Livro didático de língua portuguesa: um gênero do discurso. 2005. Dissertação (Mestrado em Linguística Aplicada) - Instituto de Estudos da Linguagem, Universidade Estadual de Campinas, Campinas/São Paulo, 2005.

CEREJA, W. R.; MAGALHÃES, T. C. Gramática: texto, reflexão e uso. São Paulo: Atual, 2012.

COHEN-SCALI, V. Alternance et identité professionnelle. Paris: PUF, 2000.

HOLQUIST, M. Dialogism: Bakhtin and his world. London: Routledge, 1994.

JODELET, D. Les Représentations sociales. Paris: PUF, 1989.

LIPIANSKY, M., TABOADA-LEONETTI, I., VASQUEZ, A. Introduction à la problématique de l'identité. In.: C. Camilleri (Ed.). Stratégies identitaires. Paris: PUF, p.7-26, 1990.

LOUSADA, E. G. Entre trabalho prescrito e realizado: um espaço para a emergência do trabalho real do professor. Tese (Doutorado em Linguística). São Paulo: Pontifícia Universidade Católica de São Paulo, 2006.

MARCUSCHI, L. A. A questão do suporte dos gêneros textuais. Projeto Integrado: "Fala e Escrita: Características e Usos", NELFE (Núcleo de Estudos Linguísticos da Fala e Escrita), Departamento de Letras da UFPE, 2003.

MARCUSCHI, L. A. Produção textual, análise de gêneros e compreensão. São Paulo: Parábola Editorial, 2008.

MATENCIO, M. L. M.; RIBEIRO, P. B. A dinâmica das e nas representações sociais: o que nos dizem os dados textuais? Estudos Linguísticos, São Paulo, 38 (3): p. 229-238, set.-dez., 2009.

MESQUITA, R. M.; MARTOS, C. R. Gramática pedagógica: volume único. São Paulo: Saraiva, 2009.

MOITA LOPES, L. P. (Org.). Por uma Linguística Aplicada Indisciplinar. São Paulo: Parábola Editorial, 2006. 
V. $10(2)$

$1-22$ maio-ago 2020

MOSCOVICI, S. La psychanalyse, son image et son public. Paris: PUF, 1961.

PONZIO, A. Signo e ideologia. In: PONZIO, A. A revolução bakhtiniana: o pensamento de Bakhtin e a ideologia contemporânea. Coordenação de tradução de Valdemir Miotello. São Paulo: Contexto, 2008.

PY, B. Représentations sociales et discours. Questions épistémologiques et méthodologiques. In: Travaux neuchâtelois de linguistique, n. 32, p. 5-20, 2000. Neuchâtel, Université de Neuchâtel (Digitalizado).

PY, B. Pour une approche linguistique des représentations sociales. In: Langages: répresentations métalinguistiques ordinaires et discours, n. 154, Paris, Larousse, 2004.

ROJO, R. H. R. Livros em sala de aula: modos de usar. In: BRASIL, MEC. Materiais Didáticos escolha e uso. 2005. p. 35-42. (Boletim 14).

ROJO, R. H. R. Materias didáticos no ensino de línguas. In.: MOITA LOPES, L. P. DA. (org). Linguística aplicada na modernidade recente. 1. ed. São Paulo: Parábola editorial, p. 163-195, 2013.

SÉRIOT, P. Vološinov e a filosofia da linguagem. Tradução: Marcos Bagno. 1. ed. São Paulo: Parábola, 2015.

SOBRAL, Adail. A filosofia primeira de Bakhtin: roteiro de leitura comentado. Campinas, SP: Mercado de Letras, 2019.

TODOROV, T. Mikahïl Bakhtine: le principe dialogique suivi de écrits du Cercle de Bakhtine. Paris: Editions du Seuil, 1981.

VOLÓCHINOV, V. A construção da enunciação e outros ensaios. São Carlos: Pedro e João Editores, 2013.

VOLÓCHINOV, V. Marxismo e filosofia da linguagem: problemas fundamentais do método sociológico na ciência da linguagem. Tradução, notas e glossário: Sheila Grillo e Ekaterina Vólkova Américo. Ensaio introdutorio: Sheila Grillo. São Paulo: Editora 34, 2017. 